\title{
OSSIFYING CHONDROMA OF METACARPAL BONE AND PHALANGES
}

\author{
G. Blundell Jones, ExeTer, ENGland
}

This case is presented because of its most unusual features and similarity to melorrheostosis.

A boy aged fourteen complained of pain and increasing deformity in his right middle finger. The finger had always been shorter than normal and limited in flexion, but, until the last two or three years, it had been of the same thickness as the others. It was apt to get in the way and to be knocked frequently, and, after such minor injuries, swelling would appear but not go down again.

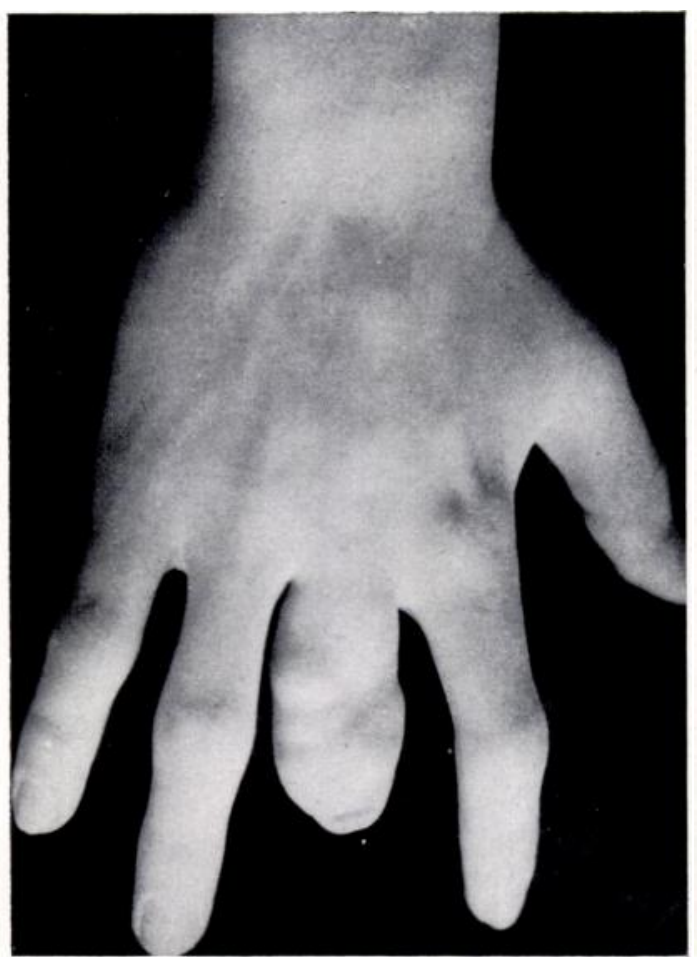

FIG. 1

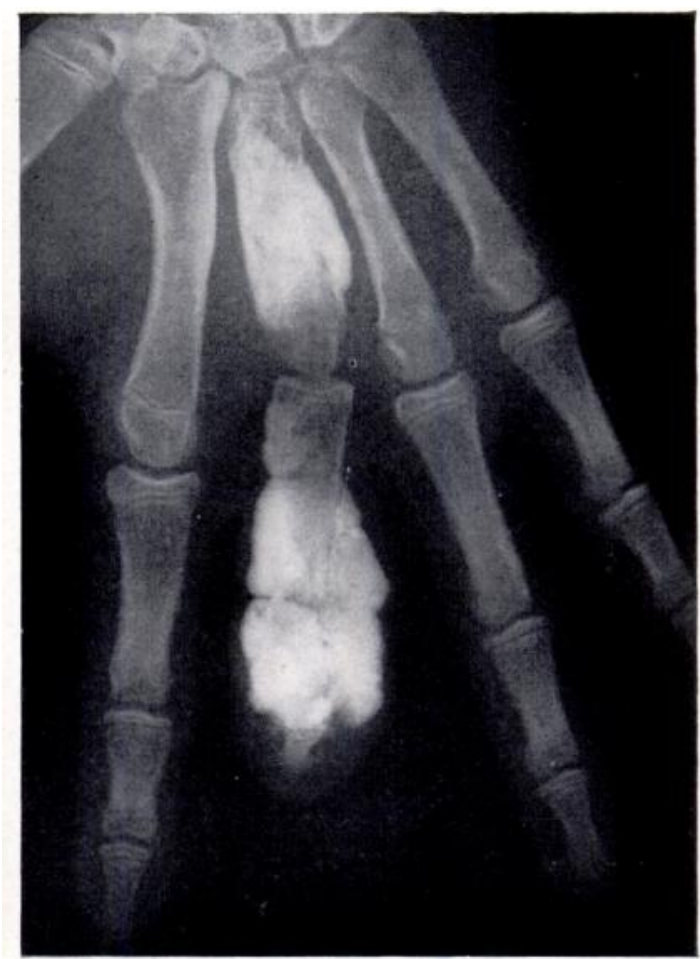

Fig. 2

Photograph and radiograph of the hand, showing the dense masses surrounding the shaft of the third metacarpal bone and the phalanges of the middle finger.

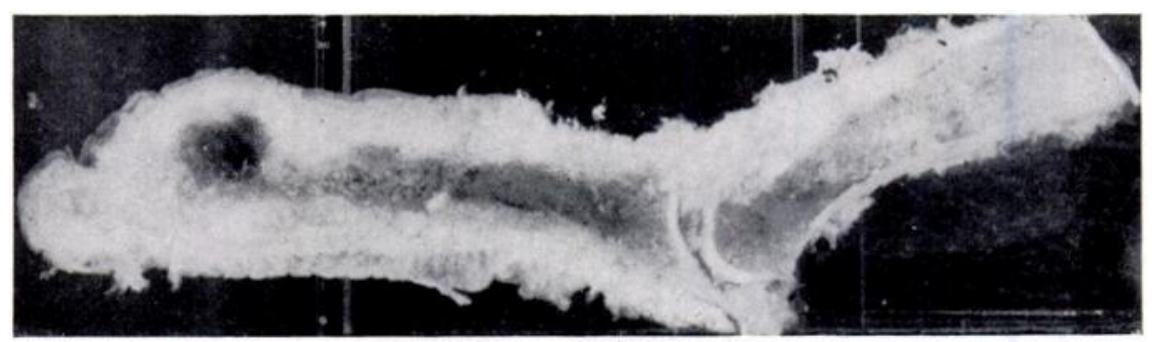

FIG. 3

Photograph of half specimen. 


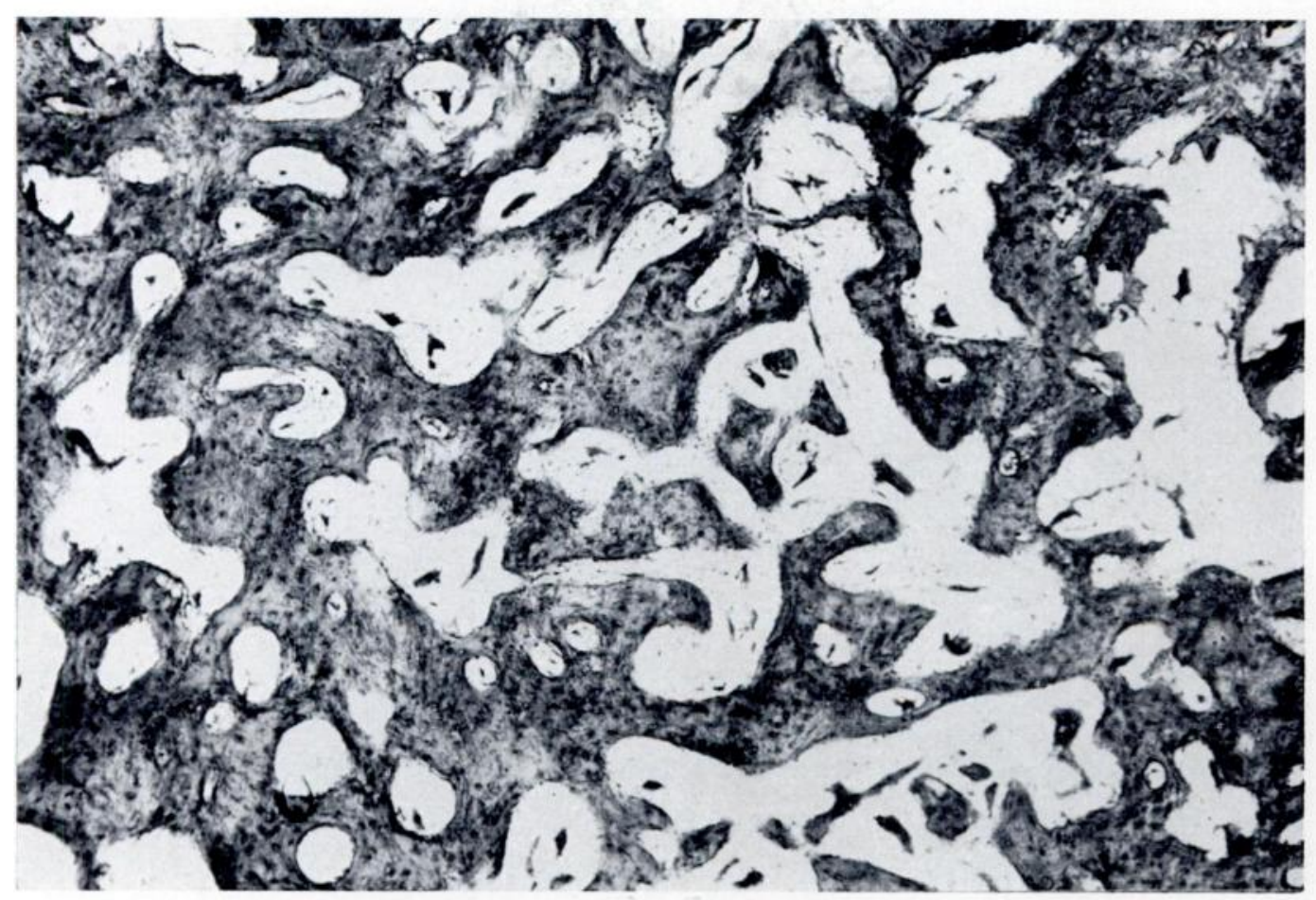

FIG. 4

Section from part of the specimen showing new bone trabeculae. (H. and E., $\times 40$.)

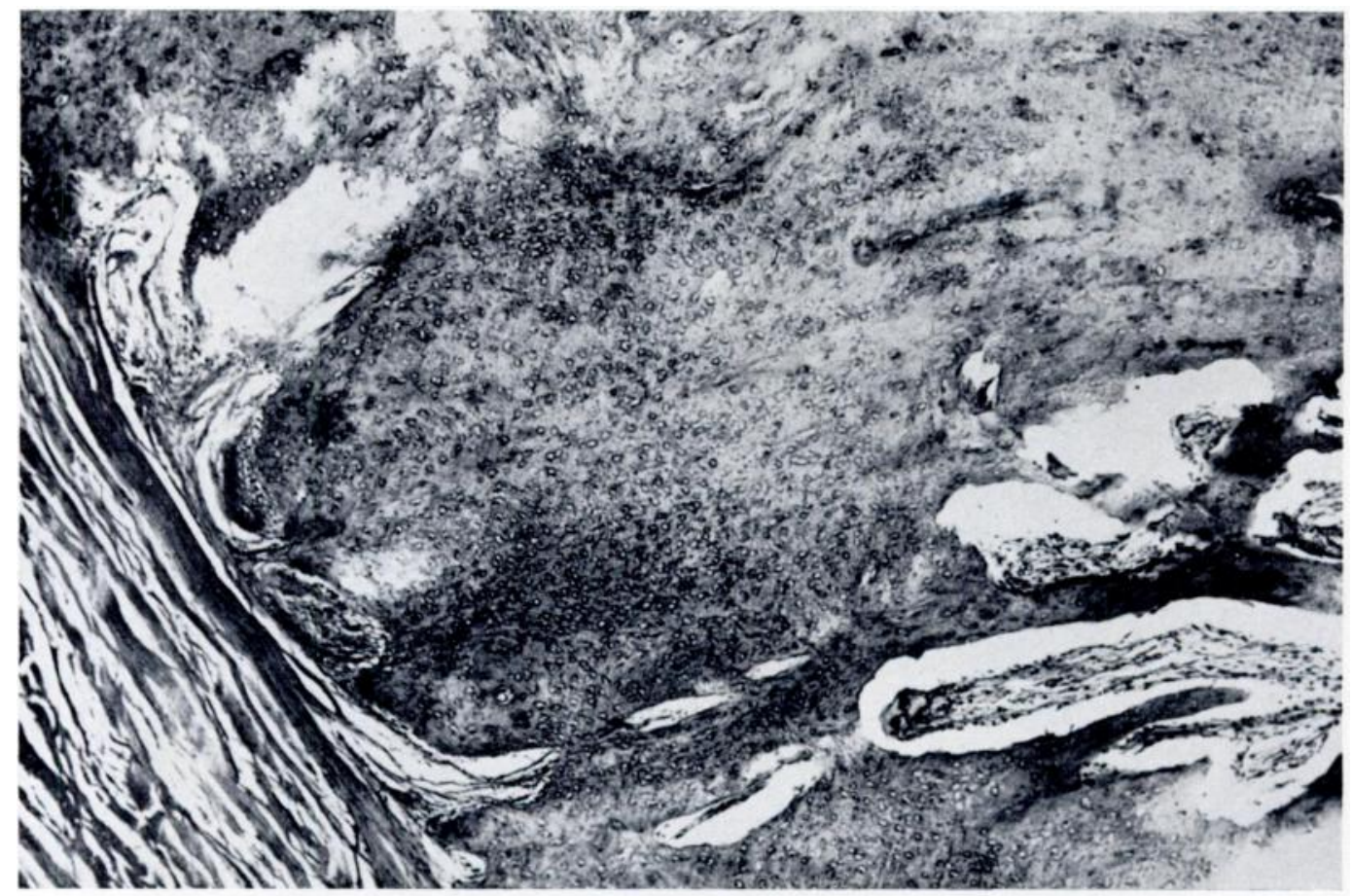

Fig. 5

Another part of the specimen, showing cartilage at the margin of new bone. (H. and E., $\times 40$.) 


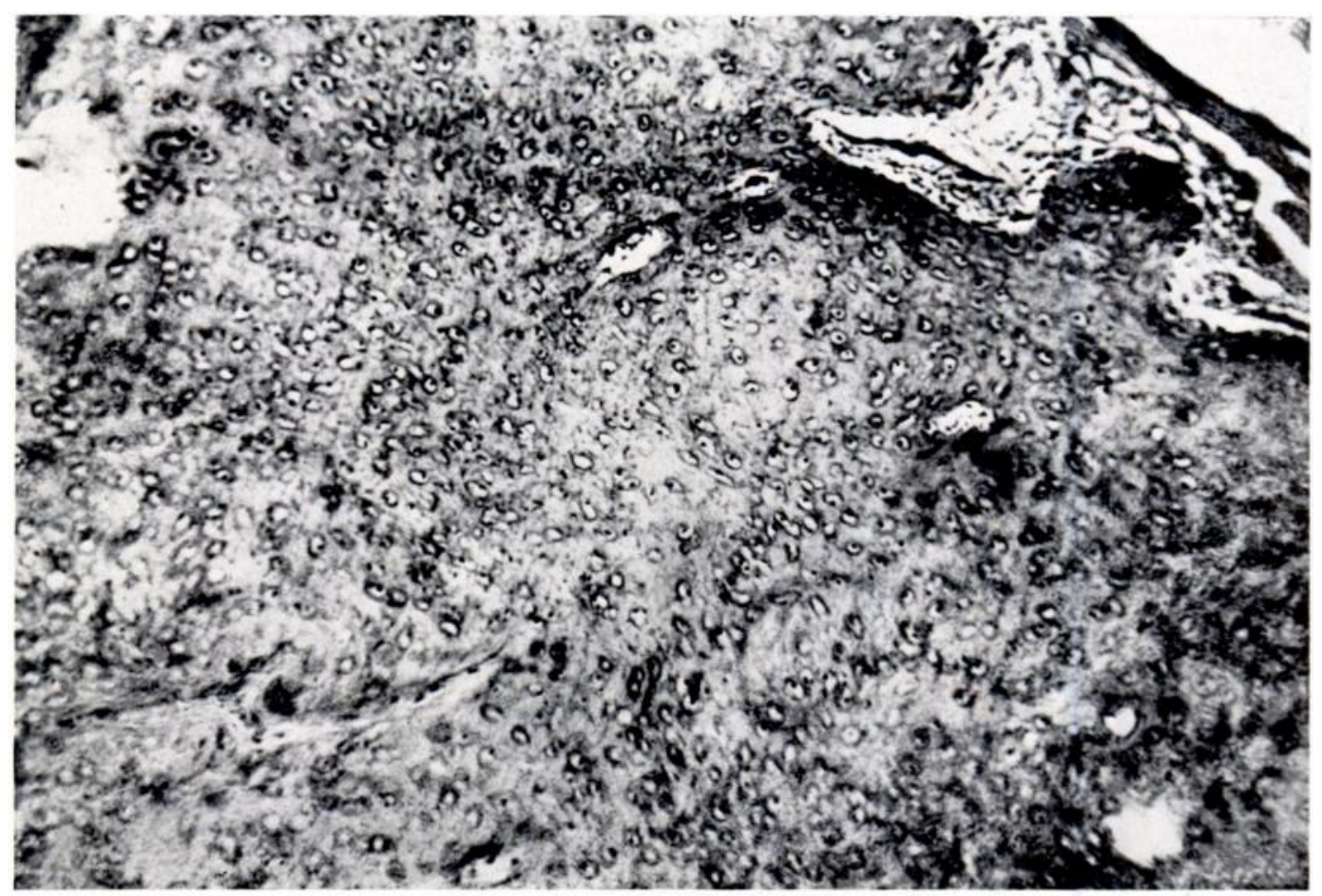

FIG. 6

A typical area of cartilage. (H. and E., 80.$)$

Examination of the finger showed the deformity illustrated (Fig. 1), with practically no movement in the interphalangeal joints and about half the normal range at the metacarpophalangeal joint. The finger was tender to pressure but showed no inflammation and the skin over it was normal. Radiographs revealed dense masses surrounding the shafts of the metacarpal bone and phalanges (Fig. 2). The other bones of the hand and right arm were normal.

Treatment-Amputation of the whole ray was performed, with carpo-metacarpal disarticulation (Fig. 3). The function and appearance of the hand are now satisfactory.

Histological examination-Sections showed that the swelling of the phalanx was due to an irregular mass of cartilage in various stages of ossification (Figs. 4 to 6). Histologically, therefore, the picture was one of a chondromatous mass being converted into bone.

I am indebted to Dr G. Stewart Smith for the pathological report and the photomicrographs. 